\title{
Identification and characterization of the 14-3-3 gene family in switchgrass
}

\author{
S. Wu ${ }^{1,2}$, H.D. Yan' ${ }^{2}$ A.L. Zhang' , L.K. Huang' , G.H. Yin ${ }^{3}$ and S. Lee \\ ${ }^{1}$ Chengdu Agricultural College, Chengdu, Sichuan, China \\ ${ }^{2}$ Department of Grassland Science, Animal Science and Technology College, \\ Sichuan Agricultural University, Chengdu, Sichuan, China \\ ${ }^{3}$ Department of Plant Biology and Pathology, Rutgers, \\ The State University of New Jersey, New Brunswick, NJ, USA \\ Corresponding author: $\mathrm{S}$. Wu \\ E-mail: nongkeyuanliujia@163.com
}

Genet. Mol. Res. 15 (4): gmr15048688

Received April 1, 2016

Accepted August 15, 2016

Published December 2, 2016

DOI http://dx.doi.org/10.4238/gmr15048688

Copyright $(C 2016$ The Authors. This is an open-access article distributed under the terms of the Creative Commons Attribution ShareAlike (CC BY-SA) 4.0 License.

\begin{abstract}
Members of the 14-3-3 family of proteins are conserved regulatory proteins that are widely found in eukaryotes and play crucial roles in diverse physiological processes, including responses to different stresses. Although genome-wide analysis of 14-3-3 proteins has been performed in a few plant species, it has not been performed in switchgrass. In this study, we identified 21 switchgrass 14-3-3 proteins (designated PvGF14a to PvGF14u) and examined genes for improved stress tolerance in this species. A phylogenetic tree was constructed to demonstrate that PvGF14 proteins can be divided into six groups, and that PvGF14 proteins belonging to each class exhibit similar gene structure. A phylogenetic analysis of PvGF14 proteins among switchgrass, Arabidopsis, and rice was conducted. Ten PvGF14 proteins were found to be orthologous to several abiotic stresses, and these were particularly responsive proteins in Arabidopsis and rice.
\end{abstract}

Genetics and Molecular Research 15 (4): gmr15048688 
Tissue-specific expression profiles showed that PvGF14a, PvGF14k, PvGF141, and PvGF14m may play significant roles in the regulation of lignin metabolism, and that PvGF14r may participate in flower development. Taken together, these data suggest that PvGF14 proteins may be involved in various biosynthesis.

Key words: 14-3-3 Protein; Genome-wide analysis; Switchgrass; Phylogenic tree; Tissue-specific expression

\section{INTRODUCTION}

Members of the G-box factor (GF14), 14-3-3 protein family, are highly conserved regulatory eukaryotic proteins that exist in distinct isoforms in numerous species (Ferl, 1996). The 14-3-3 protein was first identified as an acidic, heterodimer abundant in bovine brain, and was named according to its mobility on protein gels (25-32 kD) (Moore, 1967). These proteins have since been found to be ubiquitously expressed in all tissues, where they modulate the function of a wide range of cellular proteins. These homo- and heterodimers naturally recognize and bind phosphorylated serine or threonine residues, enabling the proteins to interact with many cellular constituents and to take part in a series of signal transduction and regulation pathways (Comparot et al., 2003; Oh et al., 2010; Pertl et al., 2011). Due to their roles in the stress response, the physiological function of 14-3-3 proteins is of great interest in plant science (Fulgosi et al., 2002). Several plant 14-3-3 proteins have been identified so far, including those from Arabidopsis thaliana (Rosenquist et al., 2001), soybean (Glycine max) (Li and Dhaubhadel, 2011), barley (Hordeum vulgare) (Finni et al., 2002), maize (Zea mays) (de Vetten and Ferl, 1994), tobacco (Nicotiana tabacum) (Piotrowski and Oecking, 1998), and tomato (Lycopersicon esculentum) (Roberts and Bowles, 1999).

Studies have shown that 14-3-3 proteins significantly condition signals that regulate many cellular activities in plants. For example, a study on the role of barley 14-3-3 isoforms in germination showed that the 14-3-3 protein gene is induced and expressed following seed imbibition (Testerink et al., 1999). The combination of certain transcription factors and the G-box binding complex in maize and Arabidopsis indicates that 14-3-3 protein genes are able to regulate signal transduction within the cell (Lu et al., 1992). In addition, transcription factors such as transcription factor IIB (TFIIB), TATA binding protein 2 (TBP2), Vivipa Rous 1 (VP1), and repression of shoot growth (RSG) were found to be target proteins of the 14-3-3 family (Schultz et al., 1998). Since 14-3-3 family members regulate the activity of many proteins involved in signal transduction, it is not surprising that many of these proteins are involved in stress responses in plants. Several studies have implicated 14-3-3 proteins in responses to environmental stresses and defense responses induced by pathogen and wounding. For example, in Arabidopsis, the expression of two 14-3-3 proteins corresponded to the expression of the genes RCI1/RCI1A and RCI2/RCI1B, which are regulated by cold stress (Jarillo et al., 1994). Furthermore, Arabidopsis 14-3-3 isoproteins combine and activate calcium-dependent protein kinase, which is another important protein involved in the stress response (Camoni et al., 1998). The Arabidopsis gene GF14 $\lambda$, which encodes a 14-3-3 protein, was introduced into cotton (Gossypium) plants in order to study its role in drought stress. In that study, transgenic cotton plants were found to have improved drought stress tolerance compared to control plants (Yan et al., 2004). In cultivated tobacco, the expression of 14-3-3 proteins can be induced by

Genetics and Molecular Research 15 (4): gmr15048688 
salt stress (Chen et al., 1994). The functions of 14-3-3 proteins in plants are broad, and include participation in nitrogen metabolism, transcription, cell cycle control, and protein transport (Moorhead et al., 1999; Finni et al., 2002).

Switchgrass (Panicum virgatum L.) is a perennial warm-season $\mathrm{C}_{4}$ grass native to North America, which has the potential to be used as a renewable biomass energy source. Switchgrass has been identified as one of the candidate energy crops in the U.S. because it has a relatively high yield and low requirements for fertilization and water (Hoogwijk et al., 2003). At present, the development of switchgrass as a bioenergy crop is complicated by the need to improve crop establishment and increase tolerance to abiotic stresses. In order to comply with state regulations, switchgrass is commonly planted on marginal land, away from food crops; therefore, it is vulnerable to many abiotic stresses, which lead to reduced yield. In addition, the physiological responses of switchgrass to various abiotic stresses have been previously reported (Azevedo Neto et al., 2004; Barney et al., 2009; Burner et al., 2009). As 14-3-3 protein genes are closely related to stress resistance in plants, there is the potential to greatly improve the efficacy of switchgrass as a biofuel. Obtaining new information on 14-3-3 proteins in switchgrass is pertinent to engineering a more efficient energy crop.

Comprehensive analysis of the gene family combined with translational genomics provides an unprecedented opportunity to predict the potential functions of 14-3-3 proteins. For instance, 10 14-3-3 protein genes have been identified in rubber tree, Hevea brasiliensis, of which, 10 genes responded to the plant hormones jasmonic acid (JA) and ethylene (ET), suggesting their involvement in JA and ET signaling (Yang et al., 2014). In a recent study, a comprehensive analysis of common bean identified 14-3-3 proteins, confirming that these proteins have a variety of functions in many cellular processes including stress responses (Li et al., 2015). In the present study, we conducted a comprehensive genome-wide analysis of switchgrass 14-3-3 proteins. Publicly available switchgrass genomic and transcriptomic databases were employed to systematically analyze the 14-3-3 protein family and to identify candidate protein genes that may contribute to development and stress tolerance in switchgrass.

\section{MATERIAL AND METHODS}

\section{Identification of 14-3-3 proteins in switchgrass}

The switchgrass draft genome and protein sequences were downloaded from the phytozome database (http://phytozome.jgi.doe.gov). The HMMER software (http://hmmer. janelia.org) was used to build the switchgrass protein database. Additionally, the Hidden Markov Model (HMM) file (PF00244) of PvGF14 was downloaded from Pfam (http://www. pfam.org) and used as a query to BLAST against the local switchgrass database (E-value $<0.001$ ). All hits were confirmed by Pfam (PF00244) and an NCBI conserved domain search (http://www.ncbi.nlm.nih.gov/Structure/cdd/wrpsb.cgi). Confirmed PvGF14 proteins were aligned using the MEGA 5.0 software package (version 5.0, www.megasoftware.net) to remove redundant sequences. The conserved PvGF14 motifs were analyzed for sequence logos using Weblogo (Crooks et al., 2004).

\section{Gene structure and phylogenetic tree analysis}

Information on the coding sequence (CDS), length of the open reading frame (ORF),

Genetics and Molecular Research 15 (4): gmr15048688 
number of introns and exons, amino acids (aa), and chromosomal location of switchgrass PvGF14 genes were retrieved from the phytozome database (http://phytozome.jgi.doe.gov). Molecular weights $(\mathrm{Da})$ and isoelectric points of 14-3-3 proteins were calculated using the ExPASy program (http://web.expasy.org/compute_pi). Exon-introns were displayed using the gene structure display server (http://gsds.cbi.pku.edu.cn).

A neighbor-joining (NJ) phylogenetic tree of PvGF14 proteins from switchgrass, Arabidopsis, and rice was built using alignments in ClustalX (1000 bootstrap replicates) via MEGA 5.0 (version 5.0, www.megasoftware.net). Two PvGF14 genes with alternative splicing sites were selected from the longest translated proteins and the duplicated result was deleted following analysis of the phylogenetic tree.

\section{Construction of chromosome location images}

The MapInspect software was used to generate chromosome location images in order to localize switchgrass PvGF14 genes. The ratio of non-synonymous and synonymous nucleotide substitutions (Ka/Ks) was obtained via the DNAsp5 software (http://www.ub.edu/ dnasp/) (Librado and Rozas, 2009).

\section{Cis-element analysis}

The PLACE database (http://www.dna.affrc.go.jp/PLACE/) was used to search for cis-elements in the promoter regions of PvGF14 genes in switchgrass. We selected a 2000-bp promoter region upstream of the start codon in each PvGF14 gene to search for possible ciselements (Manimaran et al., 2015).

\section{Analysis of gene expression in switchgrass tissues and at different developmental stages}

For each of the 21 identified PvGF14 protein genes in switchgrass, Unitranscript IDs were obtained from the PviUTs database (http://switchgrassgenomics.noble.org/) (Zhang et al., 2013). The integrated transcript sequence database was recognized by searching Unitranscript IDs in PviGEAs (http://switchgrassgenomics.noble.org/) (Zhang et al., 2013). The results obtained from the database were presented graphically in heatmap format using a $\log _{2}$-fold change following value normalization through the $\mathrm{R}$ Project software (http://miyoviqo.tha.im/).

\section{RESULTS}

\section{Identification of PvGF14 proteins in switchgrass}

We analyzed the 14-3-3 protein family and identified candidate protein genes in switchgrass. A total of 21 PvGF14 genes were identified and designated PvGF14a to PvGF14v (Table S1) following the removal of redundant and false-positive genes. The full length of PvGF14 proteins varied in length, between 101 and 314 aa long, and one protein was greater than 300 aa in length. The calculated molecular weights of proteins were between 11,205.53 and $35,248.37 \mathrm{Da}$, and the estimated isoelectric points ranged from 4.06 to 9.30 (Table S1).

Genetics and Molecular Research 15 (4): gmr15048688 


\section{Phylogenetic and structural analyses}

The NJ phylogenetic tree was constructed to show the evolutionary relationships between PvGF14 proteins (Figure 1A). A total number of six clades included 16 PvGF14 proteins. Clades I and VI contained more than three proteins, while the other clades only included two proteins. Although there were large differences between introns and exons, proteins of the same clade shared highly similar exon-intron structures of encoding genes (Figure 1B), indicating conserved exon-intron structures across all PvGF14 proteins of each clade. This strongly supports the reliability of the phylogenetic tree.
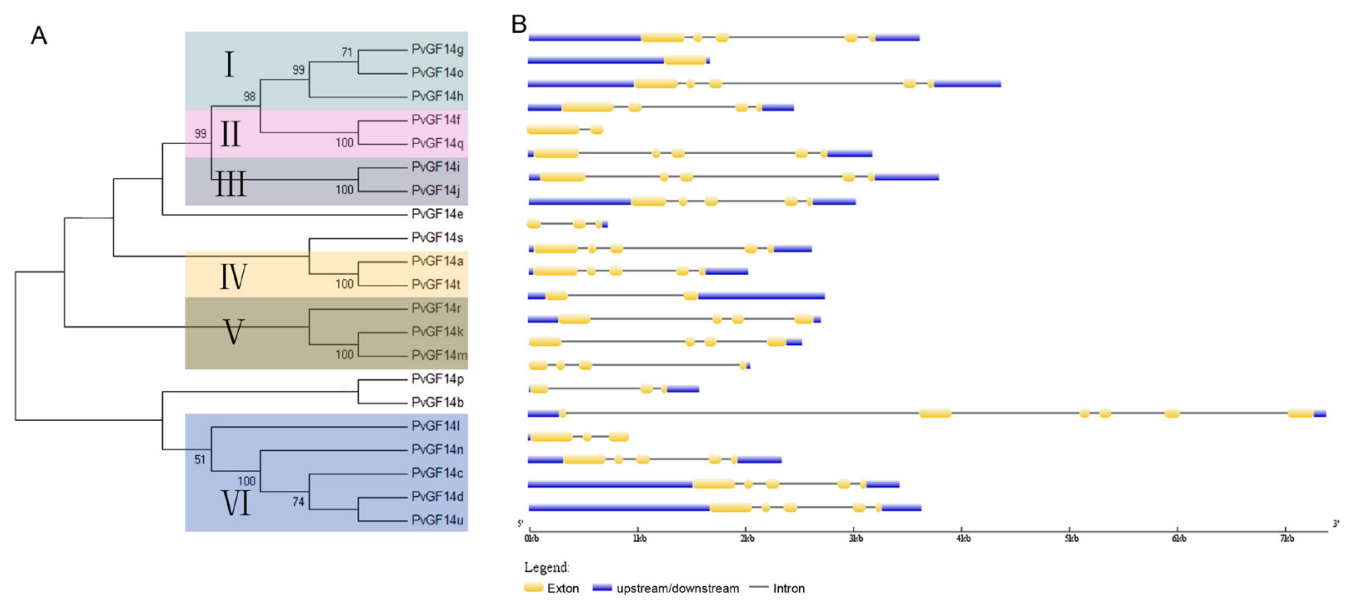

Figure 1. Phylogenetic relationship and gene structures of PvGF14 proteins. A. Multiple alignments of 21 fulllength PvGF14 proteins were conducted in ClustalX, and the phylogenetic tree was built using the neighbor-joining method with 1000 bootstrap replicates in Mega 5.0. Only scores above 50 are shown at each node. B. Exon/intron display of PvGF14 proteins in the gene structure display server. Exons and introns are represented by yellow boxes and black lines, respectively.

To further compare the evolutionary relationships of PvGF14 proteins between switchgrass and other plant species including rice and Arabidopsis, a phylogenetic analysis was conducted at the protein level (Figure 2). The analysis revealed that a large number of PvGF14 proteins clustered with paralogs of the same species. However, a few PvGF14 proteins in switchgrass were orthologous to Arabidopsis and rice proteins with functional annotations. Few abiotic stress-responsive PvGF14 proteins, such as OsGF14f, were found to be orthologous to PvGF14g, PvGF14o, and PvGF14h; OsGF14b and OsGF14e were orthologous to PvGF14a and PvGF14t; OsGF14c was orthologous to PvGF14u, PvGF14c, and PvGF14d (Chen et al., 2006). Similarly, several genes encoding growth-regulating factors, such as AtGF14phi, were orthologous to PvGF14i and PvGF14j (Liu et al., 2009).

\section{Chromosomal locations and duplications in homologous chromosomes}

Ten PvGF14 proteins were located on seven different chromosomes (chromosomes 1a, 6a, 6b, 7a, 7b, 8a, and 8b) in switchgrass. Each chromosome carried only one PvGF14 gene, with the exception of chromosome 6a, which contained four (Figure 3).

The tandem amplification and segmental duplication of chromosomal regions could

Genetics and Molecular Research 15 (4): gmr15048688 


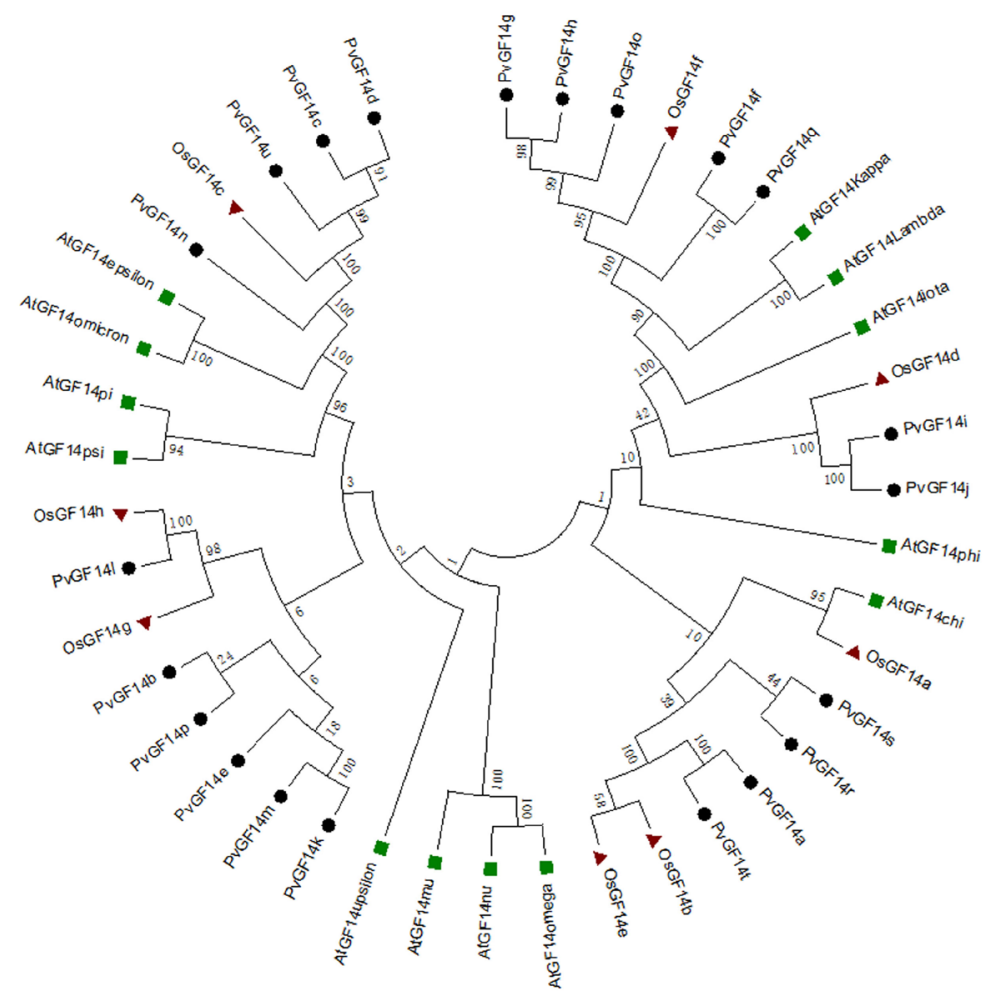

Figure 2. Phylogenetic tree of 14-3-3 proteins from switchgrass, Arabidopsis, and rice. Multiple-full-length sequences of 21 switchgrass, 13 Arabidopsis, and 8 rice 14-3-3 proteins were aligned using ClustalX, and the phylogenetic tree was built using Mega 5.0 through the neighbor-joining method with 1000 bootstrap replicates.

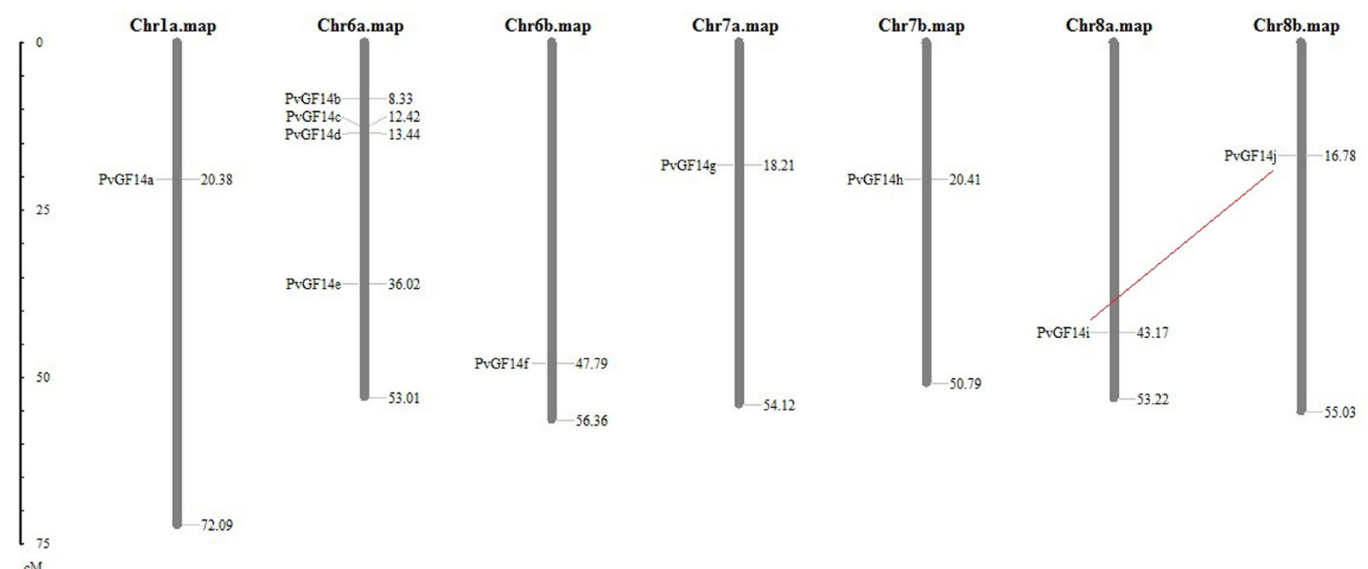

Figure 3. Chromosomal distribution of 10 PvGF14 proteins identified in this study. The dashed red line indicates duplications caused by allotetraploidy.

Genetics and Molecular Research 15 (4): gmr15048688 
be observed consistently throughout the gene family (Leister, 2004). However, PvGF14 genes located on the same chromosome were distributed far from each other (Figure 3), indicating that the switchgrass PvGF14 protein family originated from segmental duplication rather than tandem amplification. The phylogenetic tree (Figure 1A) shows that only one pair of paralogous PvGF14 proteins (PvGF14i and PvGF14j) was found within a defined chromosome location (red-lined pair in Figure 3). We then calculated the non-synonymous/synonymous substitution ratio $(\mathrm{Ka} / \mathrm{Ks})$ for this pair of proteins. Consequently, the $\mathrm{Ka} / \mathrm{Ks}$ value of PvGF14i and PvGF14j was found to be 0.805 , indicating that this pair of genes might have undergone purifying selection after duplication with limited functional divergence.

\section{Organ/tissue-level PvGF14 expression atlas identified genes potentially involved in the development of highly lignified cells and florets}

The expression patterns of 21 PvGF14 genes in tissues, organs, and at different developmental stages were evaluated using the switchgrass Gene Expression Atlas (PviGEA) (Zhang et al., 2013). Based on the expression patterns, genes (represented by corresponding probes) and samples were clustered as shown in Figure 4. Samples of reproductive organs, vegetative organs, and tissues were clearly dispersed into two clusters. Root tissue was included in the group containing reproductive organs. Overall, PvGF14 transcripts were clustered into two groups based on their patterns of expression (Figure 4). Transcripts in Group 1, comprised of PvGF14t_s_at, PvGF14a_at, PvGF14g_at, PvGF14h_at, PvGF14o_at, and PvGF14p_at, were highly expressed in all tissues, while Group 2 contained all remaining genes with relatively low expression in all tissues.

The analysis of tissue-level gene expression patterns was effective at predicting the functions of PvGF14 genes. For example, PvGF14a was expressed at low levels in less lignified tissues (e.g., florets, seeds, leaf, and leaf sheath), while it was highly expressed in lignified organs (inflorescence branches, roots, node, internode, and crown). Interestingly, the PvGF14k, PvGF14l, and PvGF14m genes showed the opposite expression pattern. Those genes were highly expressed in less lignified tissues, and exhibited reduced expression in lignified tissues. Thus, PvGF14a, PvGF14k, PvGF14l, and PvGF14m may play a significant role in the regulation of lignin metabolism. The PvGF14r gene had high expression levels in both Inflo-MER and Inflo-FLO tissues, indicating that these genes may participate in flower development. In addition, PvGF141 was homologous to OsGF14h (Figure 2), consistent with their potential contributions to the regulation of lignin metabolism.

\section{Cis-acting-regulatory elements associated with stress in switchgrass PvGF14 proteins}

We discovered that $10 \mathrm{PvGF} 14$ proteins were homologous to stress-responsive genes in Arabidopsis and rice (Figure 2). A promoter analysis was conducted on these 10 genes and their cis-elements, including abscisic acid (ABA)-responsive element (ABRE), dehydration-responsive element (DRE), C-repeat binding factors (CBFHV), and low-temperature-responsive element (LTRE) (Table 1). Among the 10 genes, PvGF14j, PvGF14c, and PvGF14g, contained the highest number of elements $(25 ; 21 ; 20)$, suggesting that these three genes may be responsive to ABA and other stresses. However, we found very little stress-responsive cis-elements in PvGF14o, PvGF14u, and PvGF14i $(1 ; 0 ; 1)$. Although they are homologous to the stress-responsive genes of Arabidopsis and rice, these three genes may not participate in the stress-response mechanism.

Genetics and Molecular Research 15 (4): gmr15048688 


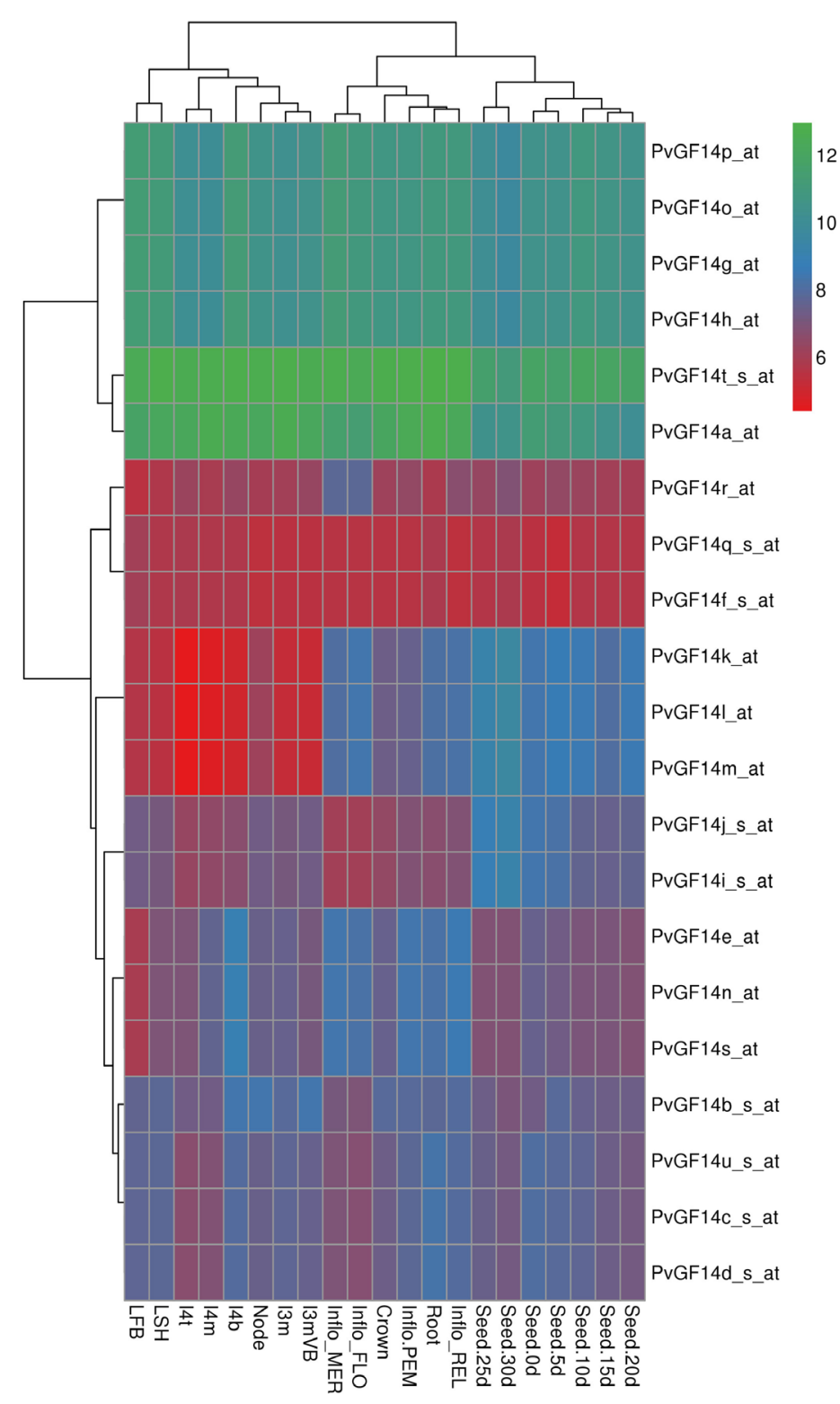

Figure 4. Heat map representation of tissue and developmental stage expression of 21 PvGF14 protein genes. Detailed information about the tissues and developmental stages is as follows. In abscissa, LFB: leaf blade; LSH: leaf sheath; I4t: top 1/5 fragment of the 4th internode; I4m: middle 1/5 fragment of the 4th internode; I4b: bottom 1/5 fragment of the 4th internode; node: plant nodes; $13 \mathrm{~m}$ : middle $1 / 5$ fragment of the $3 \mathrm{rd}$ internode; I $3 \mathrm{mVB}$ : vascular bundle derived from 1/5 fragment of the 3rd internode; Inflo-MER: inflorescence meristem; Inflo-FLO: floret of inflorescence; Crown: plant crown; Inflo-PEM: panicle emergence of inflorescence; Root: plant root; InfloREL: rachis and branch elongation of inflorescence; Seed 0d, 5d, 10d, 15d, 20d, 25d, and 30d indicate that seeds are at the anthesis stage, 5 days post-fertilization, visible caryopsis, milk stage, soft dough stage, hard dough stage, and physiological maturity, respectively. In ordinate, probes with an affix as "_s_at" means non-specific probes cross-hybridizing with a set of sequences; "_x_at" means mixed probe sets; " " at means gene-specific probes. 


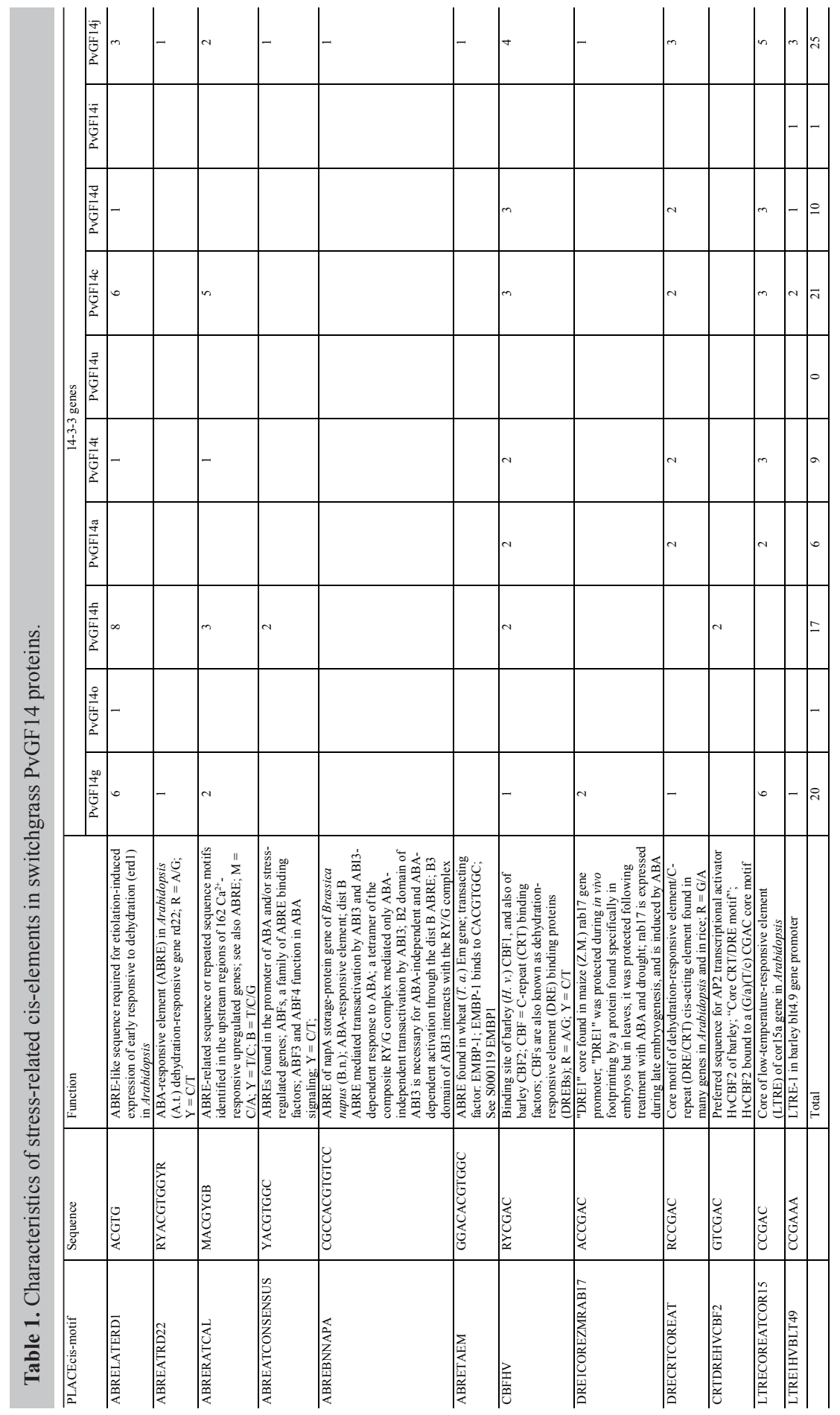

Genetics and Molecular Research 15 (4): gmr15048688 


\section{DISCUSSION}

The aim of our study was to complete a genome-wide analysis of switchgrass and to identify 14-3-3 proteins that may contribute to increased abiotic stress tolerance in this species. The phylogenetic analysis revealed that an orthologous relationship exists between switchgrass and other model plants (Figure 2). Almost half of the PvGF14 proteins identified in the present study were homologous to abiotic stress-responsive proteins in Arabidopsis and rice. Two switchgrass orthologs (PvGF14a and PvGF14t) of OsGF14b and OsGF14e were found. These two genes are important as they are involved in plant responses to indole-3 acetic acid (IAA), salicylic acid (SA), ABA, JA, heat, heavy icons, and pathogens. mRNA levels of both OsGF14b and OsGF14e in rice increased significantly in seedlings compared with control seedlings treated with IAA (Yao et al., 2007). Both transcripts were up-regulated in response to SA and JA treatment and low-temperature-responsive elements were found within their promoters. OsGF14b transcripts were up-regulated in response to ET treatment and the expression of OsGF14b increased in response to ABA treatment. Moreover, oxidative stress induced by reactive oxygen species, $\mathrm{H}_{2} \mathrm{O}_{2}$, and heavy ion, $\mathrm{Cu}^{2+}$ and $\mathrm{Cd}^{2+}$, treatments under heat stress caused an increase in the transcript level of OsGF14b (Yao et al., 2007). In another study, OsGF14b was shown to positively regulate panicle blast resistance, and negatively regulate leaf blast resistance. GF14b-mediated disease resistance is associated with SA- and JA-dependent pathways (Liu et al., 2016). It should be noted that these genes are expressed at different levels and in different plant tissues. OsGF14b transcripts were abundant in roots, low in leaves and stems, and almost absent in glumes and seeds. OsGF14e transcripts were also low in reproductive organs and abundant in vegetative organs (Yao et al., 2007). Three switchgrass orthologs (PvGF14g, PvGF14h, and PvGF14o) of OsGF14f were found to be related to cold stress. When rice was exposed to low temperatures or high salt concentrations, the levels of $\mathrm{NaCl}, \mathrm{SA}$, and JA were found to accumulate in the seedlings and calluses (Kidou et al., 1993). Similar to OsGF14b, OsGF14f transcripts were up-regulated in response to SA and JA treatments. Their promotors contain low-temperature-responsive elements. However, under heat treatment, levels of the OsGF14f transcript only increased slightly. OsGF14f was expressed in all tissues, most strongly in mature leaves, stems, roots, and glumes before pollination, and at relatively low levels in developing seeds (Yao et al., 2007). Levels of switchgrass PvGF14u, PvGF14c, and PvGF14d, which are orthologous to OsGF14c, and their transcripts, are enhanced by heat, oxidative stress caused by $\mathrm{H}_{2} \mathrm{O}_{2}$, and heavy ion, $\mathrm{Cu}^{2+}$ and $\mathrm{Cd}^{2+}$, treatments. Those genes were expressed ubiquitously in all tissues at almost equal levels. However, in response to ET treatment, levels of their transcripts fell below those observed for the control standard (Yao et al., 2007). Therefore, it is hypothesized that most PvGF14 genes that are homologous to OsGF14 are involved in stress signaling pathways.

The 14-3-3 proteins are part of a large multi-gene family. Contributing to highsequence conservation in various species, many 14-3-3 proteins have been identified in plants (Chen et al., 2006; Yang et al., 2014; Li et al., 2015). Although a high level of overlap occurs between plant proteins, which exist as different isoforms, an increasing number of studies have confirmed that variation exists in closely related species, indicating that different isoforms perform specific functions in distinct processes (Paul et al., 2012). In the present study, we identified 21 14-3-3 proteins in the switchgrass genome. These PvGF14 proteins exhibit high tissue specificity, have different functions within the cell, and interact with various partners (Rosenquist et al., 2000). Switchgrass has been considered as a front-running feedstock for

Genetics and Molecular Research 15 (4): gmr15048688 
bioenergy; however, the lignin content in plant tissue and the complexity of the cell walls limit its utilization for ethanol production, and place this plant at an economic disadvantage (Lynd et al., 2008). In the present study, transcripts of PvGF14a genes were observed at high levels in lignin tissue, while PvGF14k, PvGF14l, and PvGF14m transcripts were observed at low levels in lignin tissue, indicating that they likely play a vital role in lignin cells. Interestingly, PvGF14a and PvGF14t are the isoform pair located closest together within the phylogenetic tree (Figure 2). Intriguingly, these genes exhibit similar expression patterns in different tissues during development (Figure 4). These results suggest that PvGF14a and PvGF14t may have similar cellular functions during plant development.

Most of the gene products are closely related at both transcriptional and posttranscriptional levels. However, the temporal expression, spatial pattern, and transcript levels are dependent on the regulation of promoters present in cis-elements ( $\mathrm{Qu}$ et al., 2008). In the present study, PvGF14g, PvGF14o, and PvGF14h proteins were found to be orthologous to OsGF14f, which has previously been shown to be induced by salinity, drought, and ABA (Chen et al., 2006). The number of cis-elements for ABA and abiotic stress was high in PvGF14g $(9 ; 11)$, PvGF14h $(13 ; 4)$, and PvGF14c $(11 ; 10)$ respectively, indicating that these two proteins may be responsive to ABA and abiotic stresses. In contrast, few cis-elements were identified in PvGF14o, as well as in PvGF14u and PvGF14i, accounting for the relatively small promoter region (less than $100 \mathrm{bp}$ ) upstream of the start codon. Moreover, OsGF14b and OsGF14e, which also play a significant role in the regulation of stress and ABA response, were orthologous to PvGF14a and PvGF14t. Gene functions predicted from the phylogenetic analysis were computationally derived and may be prone to weakness. For example, no element was found in PvGF14a, indicating that this protein may not be responsive to ABA. Further functional verification should be performed to confirm the proteins identified here.

This study comprehensively classified switchgrass 14-3-3 proteins and characterized them on the basis of gene structures, phylogenetic relationships, chromosomal locations, expression profiles in different tissues, and predicted cis-elements. A total of 21 PvGF14 proteins were identified from the switchgrass genome, all of which were clustered into six groups, and had gene structures that were conserved in each group. Analysis of orthologs in the phylogenetic trees of switchgrass, rice, and Arabidopsis revealed that 10 PvGF14 proteins might be orthologous to several abiotic stress-responsive proteins, strengthening the link between 14-3-3 proteins and the stress response. Tissue-specific expression profiles showed that several PvGF14 proteins might participate in the regulation of lignin metabolism and flower development. Further research will focus on the effects of each PvGF14 protein in stress tolerance, and aim to identify possible functional interactions among these proteins.

\section{Conflicts of interest}

The authors declare no conflict of interest.

\section{ACKNOWLEDGMENTS}

Research supported by the National High-Technology Research and Development Program ("863" Program) of China (\#2012AA101801-02) and the National Natural Science Foundation of China, NSFC (\#31101760). We wish to express our warm thank to Danfeng (Chengdu) Technology Co., Ltd. Their ideas and assistance were valuable to our research.

Genetics and Molecular Research 15 (4): gmr15048688 


\section{REFERENCES}

Azevedo Neto ADD, Prisco JT, Enéas-Filho J, Lacerda CFD, et al. (2004). Effects of salt stress on plant growth, stomatal response and solute accumulation of different maize genotypes. Braz. J. Plant Physiol. 16: 31-38. http://dx.doi. org $/ 10.1590 / \mathrm{S} 1677-04202004000100005$

Barney JN, Mann JJ, Kyser GB, Blumwald E, et al. (2009). Tolerance of switchgrass to extreme soil moisture stress: ecological implications. Plant Sci. 177: 724-732. http://dx.doi.org/10.1016/j.plantsci.2009.09.003

Burner DM, Tew TL, Harvey JJ and Belesky DP (2009). Dry matter partitioning and quality of Miscanthus, Panicum, and Saccharum genotypes in Arkansas, USA. Biomass Bioenergy 33: 610-619. http://dx.doi.org/10.1016/j. biombioe. 2008.10 .002

Camoni L, Harper JF and Palmgren MG (1998). 14-3-3 Proteins activate a plant calcium-dependent protein kinase (CDPK). FEBS Lett. 430: 381-384.http://dx.doi.org/10.1016/S0014-5793(98)00696-6

Chen F, Li Q, Sun L and He Z (2006). The rice 14-3-3 gene family and its involvement in responses to biotic and abiotic stress. DNA Res. 13: 53-63. http://dx.doi.org/10.1093/dnares/ds1001

Chen Z, Fu H, Liu D, Chang PF, et al. (1994). A NaCl-regulated plant gene encoding a brain protein homology that activates ADP ribosyltransferase and inhibits protein kinase C. Plant J. 6: 729-740. http://dx.doi.org/10.1046/j.1365313X.1994.6050729.X

Comparot S, Lingiah G and Martin T (2003). Function and specificity of 14-3-3 proteins in the regulation of carbohydrate and nitrogen metabolism. J. Exp. Bot. 54: 595-604. http://dx.doi.org/10.1093/jxb/erg057

Crooks GE, Hon G, Chandonia JM and Brenner SE (2004). WebLogo: a sequence logo generator. Genome Res. 14: 11881190. http://dx.doi.org/10.1101/gr.849004

de Vetten NC and Ferl RJ (1994). Two genes encoding GF14 (14-3-3) proteins in Zea mays. Structure, expression, and potential regulation by the G-box binding complex. Plant Physiol. 106: 1593-1604. http://dx.doi.org/10.1104/ pp.106.4.1593

Ferl RJ (1996). 14-3-3 Proteins and signal transduction. Annu. Rev. Plant Physiol. Plant Mol. Biol. 47: 49-73.http://dx.doi. org/10.1146/annurev.arplant.47.1.49

Finni C, Andersen CH, Borch J, Gjetting S, et al. (2002). Do 14-3-3 proteins and plasma membrane H+-AtPases interact in the barley epidermis in response to the barley powdery mildew fungus? Plant Mol. Biol. 49: 137-147.http://dx.doi. org/10.1023/A:1014938417267

Fulgosi H, Soll J, de Faria Maraschin S, Korthout HA, et al. (2002). 14-3-3 Proteins and plant development. Plant Mol. Biol. 50: 1019-1029. http://dx.doi.org/10.1023/A:1021295604109

Hoogwijk M, Faaij A, Van Den Broek R, Berndes G, et al. (2003). Exploration of the ranges of the global potential of biomass for energy. Biomass Bioenergy 25: 119-133. http://dx.doi.org/10.1016/S0961-9534(02)00191-5

Jarillo JA, Capel J, Leyva A, Martínez-Zapater JM, et al. (1994). Two related low-temperature-inducible genes of Arabidopsis encode proteins showing high homology to 14-3-3 proteins, a family of putative kinase regulators. Plant Mol. Biol. 25: 693-704.http://dx.doi.org/10.1007/BF00029607

Kidou S, Umeda M, Kato A and Uchimiya H (1993). Isolation and characterization of a rice cDNA similar to the bovine brain-specific 14-3-3 protein gene. Plant Mol. Biol. 21: 191-194.http://dx.doi.org/10.1007/BF00039631

Leister D (2004). Tandem and segmental gene duplication and recombination in the evolution of plant disease resistance gene. Trends Genet. 20: 116-122. http://dx.doi.org/10.1016/j.tig.2004.01.007

Li R, Jiang X, Jin D, Dhaubhadel S, et al. (2015). Identification of 14-3-3 family in common bean and their response to abiotic stress. PLoS One 10: e0143280. http://dx.doi.org/10.1371/journal.pone.0143280

Li X and Dhaubhadel S (2011). Soybean 14-3-3 gene family: identification and molecular characterization. Planta 233: 569-582. http://dx.doi.org/10.1007/s00425-010-1315-6

Librado P and Rozas J (2009). DnaSP v5: a software for comprehensive analysis of DNA polymorphism data. Bioinformatics 25: 1451-1452. http://dx.doi.org/10.1093/bioinformatics/btp187

Liu D, Song Y, Chen Z and Yu D (2009). Ectopic expression of miR396 suppresses GRF target gene expression and alters leaf growth in Arabidopsis. Physiol. Plant. 136: 223-236. http://dx.doi.org/10.1111/j.1399-3054.2009.01229.x

Liu Q, Yang J, Zhang S, Zhao J, et al. (2016). OsGF14b positively regulates panicle blast resistance but negatively regulates leaf blast resistance in rice. Mol. Plant Microbe Interact. 29: 46-56. http://dx.doi.org/10.1094/MPMI-03$\underline{15-0047-R}$

Lu G, DeLisle AJ, de Vetten NC and Ferl RJ (1992). Brain proteins in plants: an Arabidopsis homolog to neurotransmitter pathway activators is part of a DNA binding complex. Proc. Natl. Acad. Sci. USA 89: 11490-11494. http://dx.doi. org/10.1073/pnas.89.23.11490

Lynd LR, Laser MS, Bransby D, Dale BE, et al. (2008). How biotech can transform biofuels. Nat. Biotechnol. 26: 169-172. http://dx.doi.org/10.1038/nbt0208-169

Genetics and Molecular Research 15 (4): gmr15048688 
Manimaran P, Raghurami Reddy M, Bhaskar Rao T, Mangrauthia SK, et al. (2015). Identification of cis-elements and evaluation of upstream regulatory region of a rice anther-specific gene, OSIPP3, conferring pollen-specific expression in Oryza sativa (L.) ssp. indica. Plant Reprod. 28: 133-142. http://dx.doi.org/10.1007/s00497-015-0264-4

Moore BW (1967). Specific acidic proteins of the nervous system. Physiol. Biochem. Asp. Nerv. Integr.: 343-359.

Moorhead G, Douglas P, Cotelle V, Harthill J, et al. (1999). Phosphorylation-dependent interactions between enzymes of plant metabolism and 14-3-3 proteins. Plant J. 18: 1-12. http://dx.doi.org/10.1046/j.1365-313X.1999.00417.x

Oh CS, Pedley KF and Martin GB (2010). Tomato 14-3-3 protein 7 positively regulates immunity-associated programmed cell death by enhancing protein abundance and signaling ability of MAPKKK $\alpha$. Plant Cell 22: 260-272. http:// dx.doi.org/10.1105/tpc.109.070664

Paul AL, Denison FC, Schultz ER, Zupanska AK, et al. (2012). 14-3-3 Phosphoprotein interaction networks - does isoform diversity present functional interaction specification? Front. Plant Sci. 3: 10.3389.

Pertl H, Rittmann S, Schulze WX and Obermeyer G (2011). Identification of lily pollen 14-3-3 isoforms and their subcellular and time-dependent expression profile. Biol. Chem. 392: 249-262. http://dx.doi.org/10.1515/bc.2011.026

Piotrowski M and Oecking C (1998). Five new 14-3-3 isoforms from Nicotiana tabacum L.: implications for the phylogeny of plant 14-3-3 proteins. Planta 204: 127-130. http://dx.doi.org/10.1007/s004250050238

Qu Q, Xing YP, Liu WX, Xu XP, et al. (2008). Expression pattern and activity of six glutelin gene promoters in transgenic rice. J. Exp. Bot. 59: 2417-2424. http://dx.doi.org/10.1093/jxb/ern110

Roberts MR and Bowles DJ (1999). Fusicoccin, 14-3-3 proteins, and defense responses in tomato plants. Plant Physiol. 119: 1243-1250. http://dx.doi.org/10.1104/pp.119.4.1243

Rosenquist M, Sehnke P, Ferl RJ, Sommarin M, et al. (2000). Evolution of the 14-3-3 protein family: does the large number of isoforms in multicellular organisms reflect functional specificity? J. Mol. Evol. 51: 446-458.

Rosenquist M, Alsterfjord M, Larsson C and Sommarin M (2001). Data mining the Arabidopsis genome reveals fifteen 14-3-3 genes. Expression is demonstrated for two out of five novel genes. Plant Physiol. 127: 142-149. http://dx.doi. org/10.1104/pp.127.1.142

Schultz TF, Medina J, Hill A and Quatrano RS (1998). 14-3-3 Proteins are part of an abscisic acid-VIVIPAROUS1 (VP1) response complex in the Em promoter and interact with VP1 and EmBP1. Plant Cell 10: 837-847.

Testerink C, van der Meulen RM, Oppedijk BJ, de Boer AH, et al. (1999). Differences in spatial expression between 14-33 isoforms in germinating barley embryos. Plant Physiol. 121: 81-88. http://dx.doi.org/10.1104/pp.121.1.81

Yan J, He C, Wang J, Mao Z, et al. (2004). Overexpression of the Arabidopsis 14-3-3 protein GF14 $\lambda$ in cotton leads to a "stay-green" phenotype and improves stress tolerance under moderate drought conditions. Plant Cell Physiol. 45 : 1007-1014. http://dx.doi.org/10.1093/pcp/pch115

Yang ZP, Li HL, Guo D, Tang X, et al. (2014). Identification and characterization of the 14-3-3 gene family in Hevea brasiliensis. Plant Physiol. Biochem. 80: 121-127. http://dx.doi.org/10.1016/j.plaphy.2014.03.034

Yao Y, Du Y, Jiang L and Liu JY (2007). Molecular analysis and expression patterns of the 14-3-3 gene family from Oryza sativa. J. Biochem. Mol. Biol. 40: 349-357. http://dx.doi.org/10.5483/BMBRep.2007.40.3.349

Zhang JY, Lee YC, Torres-Jerez I, Wang M, et al. (2013). Development of an integrated transcript sequence database and a gene expression atlas for gene discovery and analysis in switchgrass (Panicum virgatum L.). Plant J. 74: 160-173. http://dx.doi.org/10.1111/tpj.12104

\section{Supplementary material}

Table S1. Characteristics of PvGF14 proteins identified in this study. 